\title{
Hormonal regulation of pregnancy and related behavioral changes in rabbits
}

\author{
MARIA CHMURSKA-GĄSOWSKA, NATALIA SOWIŃSKA*
}

\author{
Institute of Veterinary Sciences, Center for Experimental and Innovative Medicine, \\ University Center of Veterinary Medicine JU-UA, University of Agriculture in Krakow, \\ al. Mickiewicza 21, 31-120 Krakow, Poland
}

\section{Chmurska-Gąsowska M., Sowińska N. \\ Hormonal regulation of pregnancy and related behavioral changes in rabbits}

Summary

Hormonal regulation of rabbit pregnancy and related behavioral changes has been extensively studied for the last century. The present review aimed to summarize and clarify certain aspects of this period. The article consists of six chapters describing in sequence: maternal reproductive track, gestation, maternal cyclical phenomena, pregnancy and lactation, hormonal profile in pseudo-pregnancy, behavioral changes.

Keywords: hormones, pregnancy, behavior, rabbit

Rabbit reproductive physiology has been extensively studied for the last century. The aim of this review is to summarize and draw practical conclusions from research on hormonal regulation of pregnancy and related behavioral changes.

\section{Maternal reproductive track and general information}

The rabbit uterus exists in complete duplication. There are two separate utero-cervico-vaginal canals, which fuse externally near the vagina. A corpus of the uterus is absent (46).

In the rabbit female puberty is dependent on the breed and state of nutrition. Currently, when kept indoors, the month of birth is not important for achieving maturity. Early maturing breeds can be mated at the age of 4 to 4 and $1 / 2$ months at a weight of $3 \mathrm{~kg}$. This applies to medium breeds, e.g. the New Zealand White. Females of larger breeds (e.g. Flemish Giant rabbit) mature later, i.e. at the age of 6 months.

Mature rabbit females are usually in a condition of estrus, which cannot be determined by vaginal smear. The female remains in heat up to 36 days during which time 7 to 10-day-long cycles of follicular maturation occur. Coital stimulation induces further growth with rupture of the follicles after 10 hours (46).

\section{Gestation}

Gestation is approximately 31-32 days long with the range of 30-35 days $(6,23,29)$. Pregnancy can be determined by abdominal palpation as early as 9 days of gestation (93). Implantation and placental development occur initially on day 6-7. After implantation on day 7 nutrients are initially provided by the yolk sac. During days 10-17, establishment and development of the true chorioallantoic placenta occurs (20). Histologically the placenta is hemoendothelial in character from day 22 to term, changing from endothelial-chorial.

\section{Maternal cyclical phenomena}

The female rabbit is an induced ovulator, which means that in order to allow the fertilization, the necessary ovarian hormonal preparation - the formation of large vesicles, a properly functioning hypothalamus-pituitaryovary axis and a physical factor, in the form of mating - are required. The mechanism causing ovulation in rabbits is not fully understood. The research in this field began in the 1930s and proved the important role of the pituitary gland $(32,49)$. Neuroendocrine stimulation of norepinephrine of the hypothalamus leads to the release of gonadoliberin $(\mathrm{GnRH})$, which stimulates the pituitary gland to release luteinizing hormone (LH) $(26,87,89)$. The release of LH directly causes ovarian follicular rupture and ovulation. Equine and human chorionic gonadotropin (eCG and hCG) has a similar luteotropic effect on ovaries in rabbits, as well as many other mammals $(12,91)$. Both gonadotropins are widely used in scientific studies of the pituitary and ovarian function in rabbits. However, the studies show that the abovementioned gonadotrophins affect the fertility of rabbits in varying degrees. The best effects and therefore the strongest stimulation of the pituitary gland and thus the highest birth rate, can be obtained using human chorionic gonadotropin (hCG) (47). Hashem and Aboul-ezz 
showed that when GnRH or eCG analogs where used, the implantation rate was significantly lower compared to the control group (47). Chorionic gonadotropins, in addition to luteinizing activity on the ovary, activate many proteins, including: vascular endothelial growth factor (VEGF), insulin-like growth factor (IGF-1), macrophage colony stimulating factor (M-CSF) and matrix metalloproteinase 9 (MMP-9). These factors are paracrine in the reproductive system and are responsible for preparing the environment for embryo implantation through decidualization, angiogenesis and immunomodulation $(67,68)$.

The action of the hypothalamus-pituitary-ovary axis is also influenced by factors such as the nutritional status of the female. Brecchia et al. (13) demonstrated the effect of starvation on posterior pituitary activity in response to $\mathrm{GnRH}$, folliculogenesis and ovarian steroidogenesis in rabbits. Their studies have shown that acute starvation that lasts 24 and 48 hours, significantly reduces the concentration of $\mathrm{LH}$ and $17 \beta$-estradiol. Many metabolites, including glucose, non-esterified fatty acids (NEFA), or hormones such as insulin, IGF-1, regulate ovarian function, develop ovarian follicles, as well as affect the development of pregnancy $(5,21$, 33). Ovarian function mechanism is also dependent on leptin, a hormone produced in adipose tissue. The presence of leptin receptors on ovaries (101) and in the fallopian tubes (100) has been demonstrated in rabbits. The presence of receptors for leptin suggests its importance in the formation of preovulatory follicles and for the survival of oocyte and subsequently the blastocyst in the fallopian tube. Leptin is a hormone that in a still unclear way combines metabolism and nutritional status of the body with reproductive activity (74). Studies conducted by Brecchia et al. have shown that starvation significantly reduces insulin and leptin levels in the rabbit, most likely as a result of a decrease in carbohydrate levels in the body (13). The authors suggested the possibility of a direct effect of leptin on the release of LH by the pituitary gland and secretion of estradiol by the ovaries. Probably leptin, together with other hormones, is responsible for sending a signal about the nutritional status of the organism and its condition to the structures forming the hypothalamus-pituitary gland-ovary axis. This allows the body to ration its reproductive activity.

Another hormone that can modulate the operation of the hypothalamus and pituitary in the secretion of LH-GnRH and gonadotropins, respectively, is the ghrelin-peptide hormone secreted in the stomach during fasting. Ghrelin stimulates the growth and development of ovaries in rabbits and it is also important for the proliferation of follicles (88). Sirotkin et al. showed that in the group of females treated with ghrelin before insemination, the mortality of the young fell significantly (88). The administration of the hormone, however, did not affect the number of ovulatory follicles or the birth weight of the rabbits.

The ovaries, in response to the LH signal caused by mating begin to secrete the metabolite of progesterone- $20-\alpha$ hydroxyprogesterone. Although this progestin has only $1 / 3-1 / 2$ of progesterone activity (99), it is secreted in a very large amount (51). The highest concentration of 20- $\alpha$ hydroxyprogesterone, as well as other steroid hormones like estradiol, progesterone and testosterone measured in the ovarian vein is achieved as early as 1-4 hours after mating, then the concentration of these hormones decreases and persists in low concentrations up to $1-4$ days after mating $(51,52)$. In the case of estradiol, its concentration drops to $1 / 20$ of the concentration measured in estrus. It is hypothesized that a decrease in estradiol concentration in the first days after mating is necessary to create an environment for the transport of oocytes through the fallopian tube (51). The LH peak induced by mating results in ovulation, which takes place 9-12 hours after mating and the formation of corpus luteum from the broken vesicles (83).

On the ovaries, after ovulation further follicles continue to grow and $17 \beta$-estradiol is secreted. Estradiol secretion is dependent on FSH and LH (3). The ovaries are the primary source of this hormone $(51,60)$. Moreover, estradiol is necessary for the formation of the corpus luteum and maintenance of the secretion of progesterone $(51,73)$. Estradiol is considered to be the main luteotropic factor at the beginning of rabbit pregnancies (59). The critical moment for the corpus luteum is the sixth day of pregnancy because then the corpus luteum becomes dependent on estradiol (73). Decreased estradiol concentration leads to an increase in the concentration of oxidation metabolites, an increase in cytokine concentrations and a decrease in ovarian blood flow, which directly induces regression of the corpus luteum $(10,11,37,38,44,56)$. Administration of antiestrogenic agents to a pregnant doe will lead to luteolysis, degeneration of the embryo or fetal resorption (64).

As previously described, the concentration of 17 $\beta$-estradiol, after the first peak a few hours after mating, falls to low values and remains low until the end of pregnancy. Such low concentrations of estradiol are sufficient for maintaining its luteotropic activity and ensure the activity of the corpus luteum (52). $17 \beta$-estradiol affects the structure and function of the fallopian tube through two receptor subtypes: $\operatorname{ER} \alpha$ and $\operatorname{ER} \beta(27,30,77)$. It has been proven that already 48 hours after mating there is a peak expression of genes encoding proteins for the estrogen receptor in the isthmus of fallopian tube and 72 hours after mating a similar phenomenon occurs in the ampulla of fallopian tube $(31,82)$. At the same time, different proportions of ER $\alpha$ and $E R \beta$ receptors in the isthmus and in the ampulla were found, depending on the time after mating. There is a change in the structure of the fallopian tube, as demonstrated by the variability in the proportion of Periodic acid-Schiff (PAS) + and PAS - cells in different parts of the fallopian tube, depending on the expression of receptor proteins (4). This is probably important for the transport of oocytes.

Progesterone is produced by granular cells of the ovarian theca and the corpus luteum after ovulation 
(79). This hormone is responsible for ovulation, differentiation of ovarian structures, development of the uterus and mammary gland, maintenance of pregnancy, as well as the behavioral aspect of reproductive activity $(19,22,69)$. The concentration of progesterone and its metabolites secreted by the mature corpus luteum after a primary decline, begins to increase again on the fourth day of mating (secretion: $65-85 \mu \mathrm{g} /$ ovary/hour) $(18,52)$. After implantation on the seventh day of mating it begins to grow rapidly and reaches its peak on the 14-18 day of pregnancy. Its concentration remains stable throughout the remaining duration of pregnancy (52). $20 \alpha$-progesterone is secreted by ovarian interstitial glands $(50,60)$ and by the corpus luteum $(95)$. Progesterone in the rabbit is essential for maintaining pregnancy throughout its duration (34). Lowering the concentration of this hormone in the first trimester of pregnancy leads to the inhibition of embryonic development, which results in the termination of pregnancy (84). Administration of chorionic gonadotropin on the seventh day of mating causes an increase in the number of pregnancy corpus luteum and an increase in progesterone concentration till the $18^{\text {th }}$ days of pregnancy, which leads to an increase in the fertilization rate (61). It is directly responsible for the increase in estradiol concentration which, as previously mentioned, is an important luteotropic hormone in the rabbit.

Progesterone is responsible for the preparation of myometrium, its ability to cell division and it inhibits muscle sensitivity to nervous or hormonal stimulation (oxytocin). Experimental removal of ovaries during pregnancy leads to damage in the fetuses due to the lack of inhibitory effects of progesterone on uterine contractile activity (25). Receptors for progesterone belong to the nuclear receptor super family (NRS). Two types of progesterone receptors have been identified so far: the progesterone $\alpha$ receptor (PR-A) and the progesterone $\beta$ receptor (PR-B) $(22,63)$. Ovaries have progesterone receptors and their expression is confirmed to be dependent on pituitary gonadotropins (80). Abd-Elkaremm et al. (1) have shown that PR-A receptor ablation causes abnormalities in the ovary and uterus, which can lead to female infertility, while PR-B receptor ablation causes morphogenesis disturbances in female milk ducts and alveologenesis in the fetus. At present, we do not have knowledge about the distribution and expression of progesterone receptors in the uterus during pregnancy and afterwards.

Progesterone also plays the role of an immunomodulatory factor during pregnancy by inhibiting lymphocyte proliferation and its activity $(75,78)$. However, it is known that the luteum of a pregnant female contains PR-A receptors in large and small lutein cells. Progesterone prevents the apoptosis of lutein cells by a mechanism dependent on progesterone receptors (PR), the number of which increases in granulosa cells during the preovulatory period (1).

During the preimplantation period and at the implantation itself there is an increased risk of pregnancy loss.
It is estimated that $14 \%$ of pregnancies end precisely in the period up to the seventh day of mating $(85,94)$. Success of implantation depends on a complex of factors on both the mother's and the embryo's side (48). Already at the preimplantation stage, immediately after fertilization, the embryo takes a secretory activity. In rabbit it is gonadotropin-like factors (62) that seem to inform the doe about the existence of embryos (48), affecting the maintenance of the corpus luteum activity. Gonadotropin released by the embryo also has paracrine effect on the endometrium. It stimulates decidualization, angiogenesis and modeling of immunological activity and thus prepares the uterus for implantation (92). Activin, a member of the transforming growth factor $\beta$ family (TGF- $\beta$ ), is a glycoprotein necessary for the implantation of the embryo (58). Relaxin plays a similar role to the hormone preparing for implantation. Its concentration increases within 4-9 days post coital and reaches the highest values on day 16 of pregnancy. The high concentration of relaxin persists throughout the remaining duration of pregnancy and falls on the first day after delivery (66). The placenta itself becomes a source of hormones that determine further development of pregnancy. The placenta of mammals, including rabbits, has been shown to produce leptin and ghrelin which influence growth. These are responsible for regulating appetite and metabolism $(74,81,97)$.

After implantation, many hormonal factors such as progesterone, insulin-like factors, estradiol and prostaglandins influence the development of the fetus and placenta $(24,86,90)$. The placenta is formed between the eighth and seventeenth day, which marks the start of feeding the fetus through this organ (2). During this time, i.e. up to the eighteenth day of pregnancy, the serum progesterone concentration decreases and from day 18 or 19 it remains constant almost until the end of pregnancy $(15,16,53)$. According to a study by Haneda et al. (45), on the $18^{\text {th }}$ day of pregnancy the progesterone concentration in the Japanese white rabbit was $8.8 \pm 1.0$ $\mathrm{ng} / \mathrm{ml}$. On day 28 , the concentration of this hormone was $7.7 \pm 2.3 \mathrm{ng} / \mathrm{ml}$. It is known that on the 30-32 day of pregnancy, progesterone levels begin to drop to low values. This causes a change in the ratio of progesterone to estradiol, which is the factor that triggers the beginning of the parturition. Interestingly, the estradiol concentration does not change to the extent observed in other mammalian species (52). In pigs, sheep, guinea pigs as well as in humans, estrogens reach the highest concentration just before delivery, which allows breaking the progesterone block and releasing oxytocin (7) and prostaglandins from the uterus (9).

The concentration of oxytocin in a pregnant doe is $16.1 \pm 2.0 \mathrm{pg} / \mathrm{ml}$ (36). During the parturition delivery, oxytocin concentration rises to $193 \pm 55 \mathrm{pg} / \mathrm{ml}$. The highest concentration of this hormone was found after the expulsion of the first fetus $(258 \pm 89 \mathrm{pg} / \mathrm{ml}(36)$. Oxytocin receptors are found in the genital tract throughout the entire pregnancy and their expression is possible due to the decrease in the concentration of progesterone at the very end of the third trimester $(70,71)$. 


\section{Pregnancy and lactation}

In does nursing their young ones, postpartum estrus occurs. During this time, effective mating can take place (8). The hormonal profile is essential to co-existing pregnancy and lactation. In case of co-existing pregnancy and lactation the doe's body needs to adjust the hormonal profile so that the pregnancy is sustained and there is sufficient food for the young ones (57). González-Mariscal et al. (42) conducted a study on a group of lactating pregnant females and a group of lactating non-pregnant females. The estradiol concentration was comparable in both experimental groups throughout the study period. However, the progesterone concentration in the first two trimesters was significantly higher in pregnant females (42), which was explained by the high concentration of prolactin. The hormonal profile in the last trimester was similar in both groups. The weaning of the offspring in females preparing for delivery is most likely related to the afferent stimulation of the pregnant uterus in response to oxytocin secreted during the nursing act (35). It has been proven that nursing the young ones may negatively affect the ovulatory follicle index and the number of dominant vesicles (over $1.5 \mathrm{~mm}$ ) on the sixth day of pregnancy in the ovaries of lactating females (72). This is probably due to the lower estradiol concentration in this group $(18,51)$. It has been proven that there is some antagonism between prolactin and the release of gonadotropins $(28,96)$. Prolactin begins to be secreted in the does before birth and significantly impacts the maternal behavior $(40,43)$. Prolactin receptors were also found in the hypothalamus $(17,98)$. Interestingly, not so much the suckling act itself is important for inducing the secretion of prolactin, but only the mere stimulation of the abdominal wall. This was proven by González-Mariscal and Gallegos (41), who found high concentrations of prolactin in females after mastectomy, "nursing" offspring.

\section{Hormonal profile in pseudo-pregnancy}

The progesterone concentration in pregnant and pseudo-pregnant females increases to a similar degree and its concentrations are comparable until 12-17 days after mating. Only when the corpus luteum atresia occurs in non-pregnant females does the progesterone concentration decrease and differ significantly between the two groups of females. The concentration of $17 \beta$-estradiol till the sixth day after mating does not differ between the pregnant and pseudo-pregnant females. This is due to the fact that this hormone has the same origin. It forms in follicles that remain on the ovaries and continues to grow after ovulation. As indicated earlier, this process is necessary to maintain a young corpus luteum (73). It was proven that the atresia of the corpus luteum in pseudo-pregnant females is caused by the decrease in the number of estrogen receptors on corpus luteum $(65,77)$. Research conducted by Browning et al. (14) confirmed the above assertion. The first trimester of pregnancy in a rabbit doe does not differ hormonally from the profile of a female in a pseudo-pregnant female. The moment when the doe's body detects pregnancy is significant and, in fact, it takes place a few days after the implantation. Maintaining the number of receptors for $17 \beta$ - estradiol on the corpus luteum and its further hormonal activity then becomes crucial (14).

\section{Behavioral changes}

All female mammals' sexual and maternal behavior is triggered and modulated by hormonal changes occurring during the cycle, pregnancy and lactation, as well as by such non-hormonal factors as contact with males, exposure to pups or environmental and nutritional factors. The list of sexual and maternal behaviors in rabbits is long and would require a separate review. In this study we intended to describe only the most characteristic and best studied ones.

During estrus the female domestic rabbits display a scent marking behavior called "chinning." This behavior involves rubbing of the ventral surface of her chin on objects, presumably to deposit secretion from submandibular glands. The manifestation of this behavior decreases within minutes after mating and remains at a low level throughout pregnancy and lactation (54). Therefore, the disappearance of "chinning" is treated as a behavioral transition from estrus to pregnancy and may be an important signal used by owners and breeders. A study conducted by Hoffman and GonzálezMariscal (54) aimed at finding the cause of these behavioral changes revealed, that in the first 2 hours after mating "chinning" disappearance is mediated by estrogens (mostly $17 \beta$-estradiol) and is not dependent on ovarian-derived progesterone $(\mathrm{P})$ nor progesterone receptors (PR). Later on, 24 to 96 hours after mating, the inhibition of "chinning" starts to be dependent on progesterone secretion, but is still independent of $\mathrm{PR}$, which changes in the subsequent days of pregnancy, when maternal behavior like nest building appears and which requires both $\mathrm{P}$ secretion and PR activation.

Sexual attractivity of the female, measured by the latency for the female to be mounted by male and the number of mounts, as well as sexual receptivity measured by the total number of ejaculations received total number of mounts received and aggression in the tome of the transition from estrus to pregnancy has also been studied in rabbits. The research has shown that aggression is increased by $\mathrm{P}$ secretion and PR activation, at the same time and with lightly longer latency (1-3 days) sexual behaviors are decreased (55).

Another typical rabbit maternal behavior that has been studied in the last years is nest building. It consists of building an underground nest of straw and body hair during late pregnancy. Results obtained by GonzálezMariscal indicate that prolactin has less influence on nest-building behavior than on milk production (39). The hormones most likely to influence nest building are 17 $\beta$-estradiol and progesterone because the levels of these hormones start to change at the time when the rabbits start to prepare nests. This was also confirmed by research conducted by Negatu et al. (76), which addition- 
ally indicated that the maintenance of this behavior after parturition relies on stimuli from the litter: by preventing mother-young contact at parturition or during early lactation maternal responsiveness is altered or abolished. Although prolactin is not the most important hormone in the nest building behavior, its secretion at the end of the pregnancy is extremely important for lactation, as in most mammals and behavior called "crouch over the pups" in the first days after parturition (43). What is very interesting, in contrast to most species which display a continuous interaction with their young throughout lactation, in rabbits the mother-young interaction is restricted to a minimum: a $3 \pm 5$ min bout of nursing each day, but it seems enough for maintaining lactation for the next 30 days (41).

Neuro-hormonal regulation of rabbit pregnancy, which also influences behavioral changes during this period, is complicated and, despite of being studied for many years, not fully characterized. We hope that this review makes it possible to clarify certain aspects of this period and may become a contribution to further research in this field.

\section{References}

1. Abd-Elkareem M.: Cell-specific immuno-localization of progesterone receptor alpha in the rabbit ovary during pregnancy and after parturition. Anim. Reprod. Sci. 2017, 180, 100-120.

2. Adams C. E.: Prenatal mortality in the rabbit Oryctolagus cuniculus. Reproduction 1960, 1, 36.

3. Adams T. E., Boime I.: The Expanding Role of Recombinant Gonadotropins in Assisted Reproduction. Reprod. Domest. Anim. 2008, 43, 186-192.

4. Anzaldúa S. R., Camacho-Arroyo I., Cerbón M. A.: Histomorphological changes in the oviduct epithelium of the rabbit during early pregnancy. Anat. Histol. Embryol. 2002, 31, 308-312.

5. Ashworth C. J., Beattie L., Antipatis C., Vallet J. L.: Effects of pre- and post-mating feed intake on blastocyst size, secretory function and glucose metabolism in Meishan gilts. Reprod. Fertil. Dev. 1999, 11, 323-327.

6. Austin C. R.: The Mammalian Egg. Blackwell, Oxford 1961.

7. Bedford C. A., Challis J. R., Harrison F. A., Heap R. B.: The role of oestrogens and progesterone in the onset of parturition in various species. J. Reprod. Fertil. 1972, 16, 1-23.

8. Beyer C., Rivaud N.: Sexual behavior in pregnant and lactating domestic rabbits. Physiol. Behav. 1969, 4, 753-757.

9. Blatchley F., Donovan B., Poyser N., Horton E.: Identification of prostaglandin F2 $\alpha$ in the utero-ovarian blood of guinea pig after treatment with oestrogen. Nature 1971, 230, 243-244.

10. Boiti C., Guelfi G., Zerani M., Zampini D., Brecchia G., Gobbetti A.: Expression patterns of cytokines, p53 and nitric oxide synthase isoenzymes in corpora lutea of pseudopregnant rabbits during spontaneous luteolysis. Reproduction 2004, 127, 229-238

11. Boiti C., Zampini D., Brecchia G., Gobbetti A., Zerani M.: Regulation of nitric oxide synthase isoforms and role of nitric oxide during prostaglandin F2 $\alpha$-induced luteolysis in rabbits. Reproduction 2003, 125, 807-816.

12. Brambell W. R., Parkes A. S.: Studies on ovulation: VI. relative importance of concentration and absolute amount of the ovulation- producing hormone. J. Physiol. 1932, 74, 173-178.

13. Brecchia G., Bonanno A., Galeati G. et al.: Hormonal and metabolic adaptation to fasting: Effects on the hypothalamic-pituitary-ovarian axis and reproductive performance of rabbit does. Domest. Anim. Endocrinol. 2006, 31, 105-122.

14. Browning J., Reyes L., Wolf R.: Comparison evidence of serum progesterone in pregnant rabbits : recognition of pregnancy and estradiol-1713 and pseudopregnant for postimplantation rate. Biol. Reprod. 1980, 23, 1014-1019.

15. Browning $J . W . R$. : Maternal recognition effect of pregnancy in the rabbit: effect of conceptus removal. Biol. Reprod. 1981, 24, 293-297.

16. Browning J. Y., Amis M. M., Meller P. A., Bridson W. E., WolfR. C.: Luteotropic and antiluteolytic activities of the rabbit conceptus. Biol. Reprod. 1982, 27, 665-672.

17. Di Carlo R., Muccioli G.: Presence of specific prolactin binding sites in the rabbit hypothalamus. Life Sci. 1981, 28, 2299-2307.
18. Challis J. R. G., Davies I. J., Ryan K. J.: The concentrations of progesterone, estrone and estradiol-17 in the plasma of pregnant rabbits. Endocrinology 1973, 93, 971-976

19. Clarke C. L., Sutherland R. L.: Progestin regulation of cellular proliferation. Endocr. Rev. 1990, 11, 266-301.

20. Cliff M. M., Reynolds S. R. M.: A dose-stress response of adrenaline affecting fetuses at a critical time in pregnant rabbits. Anat. Rec. 1959, 134, 379-384.

21. Comin A., Gerin D., Cappa A., et al.: The effect of an acute energy deficit on the hormone profile of dominant follicles in dairy cows. Theriogenology 2002, 58, 899-910

22. Conneely O. M., Mulac-Jericevic B., Lydon J. P.: Progesterone-dependent regulation of female reproductive activity by two distinct progesterone receptor isoforms. Steroids 2003, 68, 771-778

23. Cozens D. D.: Abnormalities of the External Form and of the Skeleton in the New Zealand White Rabbit. Food Cosmet.Toxicol. 1965, 3, 695-700.

24. Crossey P. A., Pillai C. C., Miell J. P.: Altered placental development and intrauterine growth restriction in IGF binding protein-1 transgenic mice. J. Clin. Invest. 2002, 110, 411-418.

25. Csapo A.: Progesterone: its regulatory effect on the myometrium, [in:] Wolstenholme G. E. W., Knecht J. (ed.), J. \& A. Churchill, Ltd, London 1969, 13-55.

26. Dal Bosco A., Rebollar P. G., Boiti C., Zerani M., Castellini C.: Ovulation induction in rabbit does: Current knowledge and perspectives. Anim. Reprod. Sci. 2011, 129, 106-117.

27. Diel P.: Tissue-specific estrogenic response and molecular mechanisms. Toxicol. Lett. 2002, 127, 217-224.

28.Durand P., Djiane J.: Lactogenic activity in the serum of rabbits during pregnancy and early lactation. J. Endocrinol. 1977, 75, 33-42.

29. Eckstein P., Zuckerman S.: The oestrus cycle in the mammalia, [in:] A. S. Parkers (ed). Marshall's Physiology of Reproduction, Longmans, New York 1962, 226-396

30. Edwards D. P.: Regulation of signal transduction pathways by estrogen and progesterone. Annu. Rev. Physiol. 2005, 67, 335-376.

31. El-Banna A., Sacher B.: A study on steroid hormone receptors in the rabbit oviduct and uterus during the first few days after coitus and during egg transport. Biol. Reprod. 1977, 17, 1-8

32. Fee A. R., Parkes A. S.: Studies on ovulation: I. The relation of the anterior pituitary body to ovulation in the rabbit. J. Physiol. 1929, 67, 383-388.

33. Ferguson E. M., Ashworth C. J., Edwards S. A., Hawkins N., Hepburn N., Hunter $M$. G.: Effect of different nutritional regimens before ovulation on plasma concentrations of metabolic and reproductive hormones and oocyte maturation in gilts. Reproduction 2003, 126, 61-71.

34. Fortun-Lamothe L., Prunier A., Bolet G., Lebas F.: Physiological mechanisms involved in the effects of concurrent pregnancy and lactation on foetal growth and mortality in the rabbit. Livest. Prod. Sci. 1999, 60, 229-241.

35. Fuchs A. R., Cubile L., Yusoff Dawood M., Stener Jøorgensen F.: Release of oxytocin and prolactin by suckling in rabbits throughout lactation. Endocrinology 1984, 114, 462-469.

36. Fuchs A. R., Dawood M. Y.: Oxytocin release and uterine activation during parturition in rabbits. Endocrinology 1980, 107, 1117-1126.

37. Gadsby J. E., Keyes P. L.: Control of corpus luteum function in the pregnant rabbit: role of the placenta ("placental luteotropin") in regulating responsiveness of corpora lutea to estrogen. Biol. Reprod. 1984, 31, 16-24.

38. Gadsby J. E., Keyes P. L., Bill C. H.: Control of corpus luteum function in the pregnant rabbit: Role of estrogen and lack of a direct luteotropic role of the placenta. Endocrinology 1983, 113, 2255-2262.

39. González-Mariscal G.: Neuroendocrinology of maternal behavior in the rabbit Horm. Behav. 2001, 40, 125-132.

40. González-Mariscal G., Chirino R., Flores-Alfonso J. C., Rosenblatt J. S., Beyer $C$.: Intracerebroventricular injections of prolactin counteract the antagonistic effect of bromocriptine on rabbit maternal behaviour. J. Neuroendocrinol. 2004, 16, 949-955.

41. González-Mariscal G., Gallegos J. A.: The maintenance and termination of maternal behavior in rabbits: Involvement of suckling and progesterone. Physiol. Behav. 2014, 124, 72-76.

42. González-Mariscal G., Gallegos J. A., Sierra-Ramirez A., Flores J. G.: Impact of concurrent pregnancy and lactation on maternal nest-building, estradiol and progesterone concentrations in rabbits. World Rabbit Sci. 2009, 17, 145-152.

43. González-Mariscal G., Melo A. I. Parlow A. F. Beyer C., Rosenblatt J. S Pharmacological evidence that prolactin acts from late gestation to promote maternal behaviour in rabbits. J. Neuroendocrinol. 2000, 12, 983-992.

44. Goodman S. B., Kugu K., Chen S. H. et al.: Estradiol-mediated suppression of apoptosis in the rabbit corpus luteum is associated with a shift in expression of bcl-2 family members favoring cellular survival. Biol. Reprod. 1998, 59, 820-827.

45. Haneda R., Mizoguchi Y., Matsuoka T., Mizuguchi H., Endoh T., Fukuda K., Asano $Y$ : Changes in blood parameters in pregnant Japanese White rabbits. J. Toxicol. Sci. 2010, 35, 773-778.

46. Hartman H. A.: The Fetus in Experimental Teratology, [in:] Weisbroth S. H., Flatt R. E., Krau A. L. (eds): The Biology of the Laboratory Rabbit. Elsevier 1974, p. 91-153. 
47. Hashem N. M., Aboul-ezz Z. R.: Effects of a single administration of differen gonadotropins on day 7 post-insemination on pregnancy outcomes of rabbit does. Theriogenology 2018, 105, 1-6.

48. Herrler A., von Rango U., Beier H. M.: Embryo-maternal signalling: How the embryo starts talking to its mother to accomplish implantation. Reprod. Biomed Online 2003, 6, 244-256.

49. Hill M., Parkes A. S.: Studies on ovulation: IV. Induction of ovulation in the hypophysectomized rabbit by administration of anterior lobe extracts. J. Physiol. 1931, 71, 36-39.

50. Hilliard J., Archubald D., Sawyer C. H.: Gonadotropic activation of prevulatory synthesis and release of progestin in the rabbit. Endocrinology 1963, 72, 59-66.

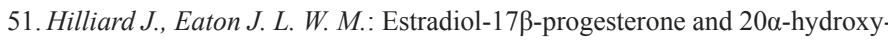
pregan-4-en-3-one in rabbit ovarian venous plasma. Endocrinology 1971, 89, 522-527.

52. Hilliard J., Scaramuzzi R. J., Penardi R., Sawyer C. H.: Progesterone, Estradiol and Testosterone levels in ovarian venous blood of pregnant rabbits. Endocrinology 1973, 93, 1235-1238.

53. Hilliard J., Spies H. G., Sawyer C. H.: Cholesterol storage and progestin secretion during pregnancy and pseudopregnancy in the rabbit. Endocrinology 1968, Jan 82 (1), 157-165.

54. Hoffman K. L., González-Mariscal G.: Relevance of ovarian signaling for the early behavioral transition from estrus to pregnancy in the female rabbit. Horm. Behav. 2007, 52, 531-539.

55. Hoffman K. L., Martinez-Alvarez E., Rueda-Morales R. I.: The inhibition of female rabbit sexual behavior by progesterone: Progesterone receptordependent and-independent effects. Horm. Behav. 2009, 55, 84-92.

56. Holt J. A.: Regulation of progesterone production in the rabbit corpus luteum. Biol. Reprod. 1989, 40, 201-208.

57. Hudson R., Bilko A., Altbacker V.: Nursing, weaning and the development of independent feeding in the rabbit (Oryctolagus cuniculus). Int. J. Mamm. Biol. 1996, 61, 39-48.

58. Jones R. L., Findlay J. K., Farnworth P. G., Robertson D. M., Wallace E., Salamonsen L. A.: Activin A and inhibin a differentially regulate human uterine matrix metalloproteinases: Potential interactions during decidualization and trophoblast invasion. Endocrinology 2006, 147, 724-732.

59. Keyes P. L., Armstrong D. T.: Endocrine role of follicles in regulation of corpus luteum function in the rabbit. Endocrinology 1968, 83, 509-515.

60. Keyes P. L., Nalbandov A. V.: Maintenance and Function of Corpora Lutea in Rabbits Depend on Estrogen. Endocrinology 1967, 80, 938-946.

61. Keyes P. L., Possley R. M., Yuh K. C. M.: Contrasting effects of oestradiol-17 and human chorionic gonadotrophin on steroidogenesis in the rabbit corpus luteum. J. Reprod. Fertil. 1983, 69, 579-586.

62. Khan-Dawood F. S., Dawood M. Y.: Chorionic gonadotropin receptors and immunoreactive chorionic gonadotropin in implantation of the rabbit blastocyst. Am. J. Obstet. Gynecol. 1984, 148, 359-365.

63. Kubota K., Cui W., Dhakal P. et al.: Rethinking progesterone regulation of female reproductive cyclicity. Proc. Natl. Acad. Sci. [Internet] 2016, 113, 4212-4217.

64. Labhsetwar A. P.: Effect of antioestrogen on corpus luteum function of rabbits and rats. J. Reprod. Fertil. 1971, 25, 294-297.

65. Lee C., Keys P., Jacobson H.: Estrogen receptor in rabbits corpus luteum. Science 1971, 173, 1032-1033.

66. Lee V. H., Fields P. A.: Rabbit Relaxin: The Influence of Pregnancy and Ovariectomy during Pregnancy on the Plasma Profile1. Biol. Reprod. 1991, 45, 209-214

67.Licht P., Lösch A., Dittrich R., Neuwinger J., Siebzehnrübl E., Wildt L. Novel insights into human endometrial paracrinology and embryo-maternal communication by intrauterine microdialysis. Hum. Reprod. Update 1998, 4, $532-538$

68. Licht P., Russu V., Wildt L.: On the role of human chorionic gonadotropin (hCG) in the embryo-endometrial microenvironment: implications for differentiation and implantation. Semin. Reprod. Med. 2001, 19, 37-47.

69. Lydon J. P., DeMayo F. J., Funk C. R., et al.: Mice lacking progesterone receptor exhibit pleiotropic reproductive abnormalities. Genes. Dev. 1995, 9, 2266-2278.

70. Maggi M., Genazzani A. D., Giannini S. et al:: Vasopressin and oxytocin receptors in vagina, myometrium, and oviduct of rabbits. Endocrinology 1988 , 122, 2970-2980

71. Maggi M., Peri A., Giannini S., Fantoni G., Guardabasso V., Serio M. Oxytocin and V1 vasopressin receptors in rabbit endometrium during pregnancy. J. Reprod. Fertil. 1991, 91, 575-581.

72. Marongiu M. L., Dimauro C.: Preliminary study on factors influencing rabbit doe reproductive efficiency: Effect of parity, day of mating, and suckling on ovarian status and estrogen levels at day 6 of pregnancy. Can. J. Vet. Res. 2013, 77, 126-130

73. Miller J. B., Keyes P. L.: Transition of the rabbit corpus luteum to estrogen dependence during early luteal development. Endocrinology 1978, 83, 314 -322 .
74. Moschos S., Chan J. L., Mantzoros C. S.: Leptin and reproduction: A review. Fertil. Steril. 2002, 77, 433-444.

75. Ndiaye K., Poole D. H., Walusimbi S. et al.: Progesterone effects on lymphocytes may be mediated by membrane progesterone receptors. J. Reprod. Immunol. 2012, 95, 15-26.

76. Negatu Z., McNitt J. I.: Hormone profiles and nest-building behavior during the periparturient period in rabbit does. Anim. Reprod Sci. 2002, 72, 125-135.

77. Nilsson S., Mäkelä S., Treuter E. et al.: Mechanisms of Estrogen Action. Physiol. Rev. [Internet] 2001, 81, 1535-1565.

78. Pate J. L., Keyes P. L.: Immune cells in the corpus luteum: Friends or foes? Reproduction 2001, 122, 665-676.

79. Peluso J. J.: Multiplicity of Progesterone's Actions and Receptors in the Mammalian Ovary1. Biol. Reprod. 2006, 75, 2-8.

80. Pinter J. H., Deep C., Park-Sarge O. K.: Progesterone receptors: Expression and regulation in the mammalian ovary. Clin. Obstet. Gynecol. 1996, 39, 424-435.

81.Prentice A. M., Moore S. E., Collinson A. C., O'Connell M. A.: Leptin and undernutrition, [in:] Nutrition Reviews 2002, Oct 60 (10 Pt 2), 56-67.

82. Puri R. K., Roy S. K.: Estradiol binding in different parts of the rabbit oviduct during egg transport. Endocrinologie 1989, 78, 12-20.

83. Ramirez V. D., Beyer C.: The ovarian cycle of the rabbit: its neuroendocrine control, [in:] Knobil E. K., Neils J. D. (eds): The Physiology of Reproduction. Raven Press, New York 1988, p. 1873-1892.

84. Salem A. A., Gomaa Y. A.: Effect of combination vitamin E and single longacting progesterone dose on enhancing pregnancy outcomes in the first two parities of young rabbit does. Anim. Reprod. Sci. 2014, 150, 35-43.

85. Santacreu M. A., Mocé M. L., Climent A. et al.: Divergent selection for uterine capacity in rabbits. II. Correlated response in litter size and its components estimated with a cryopreserved control population. J. Anim. Sci. 2005, 83, 2303-2307.

86. Seshagiri P. B., Sen Roy S., Sireesha G., Rao R. P.: Cellular and molecula regulation of mammalian blastocyst hatching. J. Reprod. Immunol. 2009, 83, 79-84.

87. Sirotkin A., Curlej J.: Effect of 3-isobutyl-methyl-xanthine on rabbit superovulation and egg recovery Effect of 3-isobutyl-1-methyl-xanthine on rabbit superovulation and egg recovery. Slovak J. Anim. Sci. 2008, 41, 57-59.

88. Sirotkin A. V., Chrenek P., Kolesarová A., Parillo F., Zerani M., Boiti C.: Novel regulators of rabbit reproductive functions. Anim. Reprod. Sci. 2014, 148, 188-196.

89. Sirotkin A. V., Chrenek P., Rafay J. et al.: Some endocrine traits of transgenic rabbits. I. Changes in plasma and milk hormones. Physiol. Res. 2008, 57, 735-743.

90. Spencer T. E., Burghardt R. C., Johnson G. A., Bazer F. W.: Conceptus signals for establishment and maintenance of pregnancy. Anim. Reprod. Sci. 2004, 82-83, 537-550.

91. Spies H. G., Pau K. Y., Yang S. P.: Coital and estrogen signals: a contrast in the preovulatory neuroendocrine networks of rabbits and rhesus monkeys. Biol. Reprod. 1997, 56, 310-319.

92. Srisuparp S., Strakova Z., Fazleabas A. T.: The role of chorionic gonadotropin (CG) in blastocyst implantation. Arch. Med. Res. 2001, 32, 627-634.

93. Suitor A. E.: Palpating domestic rabbits to determine pregnancy. US Dep. Agri. Bull. 1946, 245, 1-4

94. Tao T., Niemann H.: Cellular characterization of blastocysts derived from rabbit 4-, 8- and 16-cell embryos and isolated blastomeres cultured in vitro. Hum. Reprod. 2000, Apr. 15(4), 881-889.

95. Telegdy G., Savard K.: Steroid formation in vitro in rabbit ovary. Steroids 1966, 8, 685-694.

96. Theau-Clément M. R. A.: A study on relationships between receptivity and lactation in the doe and their influence on reproductive performances. J. App. Rabbit Res. 1992, 15, 412-421.

97. Tschop M., Smiley D. L., Heiman M. L.: Ghrelin induces adiposity in rodents. Nature 2000, 407, 908-913.

98. Walsh R. J., Mangurian L. P., Posner B. I.: The distribution of lactogen receptors in the mammalian hypothalamus: an in vitro autoradiographic analysis of the rabbit and rat. Brain Res. 1990, 530, 1-11.

99.Zander J., Forbes T. R., Von Münstermann A. M., Neher R.: Delta 4-3-Ketopregnene-20 alpha-ol and delta 4-3-ketopregnene-20 beta-ol, two naturally occurring metabolites of progesterone; isolation, identification, biologic activity and concentration in human tissues. J. Clin. Endocrinol. Metab. 1958, 18, 337-353.

100. Zerani M., Boiti C., Dall'Aglio C. et al.: Leptin receptor expression and in vitro leptin actions on prostaglandin release and nitric oxide synthase activity in the rabbit oviduct. J. Endocrinol. 2005, 185, 319-325.

101. Zerani M., Boiti C., Zampini D. et al.: Ob receptor in rabbit ovary and leptin in vitro regulation of corpora lutea. J. Endocrinol. 2004, 183, 279-288.

Corresponding author: Maria Chmurska-Gąsowska DVM, al. Mickiewicza 21, 31-120 Krakow, Poland; e-mail: maria.chmurska-gasowska@ urk.edu.pl 